\title{
LOS HECHOS JURÍDICOS
}

\section{Rubén Compagnucci de Caso}

\author{
Universidad Nacional de La Plata \\ compagnuccidecaso@gmail.com
}

Recibido: 4/09/2020

Aceptado: 29/09/2020

\section{Resumen}

Este estudio está dedicado al tema que trata sobre "los hechos jurídicos". Dicha cuestión integra un sector de la denominada "parte general del derecho privado". La mayoría de los códigos civiles del siglo XX y XXI que contienen esa parte general dedican varios de sus artículos a reglar sobre dicha materia y establecer, de este modo, su naturaleza, requisitos y efectos.

Ejemplo de todo ello son los códigos de Alemania (BGB), Brasil, México Suiza y otros más. El nuevo Código Civil y Comercial que rige en la Argentina desde el 1 de agosto de 2015 trata ese tema en el Libro I, Título V, Capítulo I, artículos 257 a 264.

Los hechos son acontecimientos exteriores de la realidad social que tienen como efecto producir alteración o modificación en el medio que los rodea. Aquí, su análisis y estudio se apoyan solamente sobre aquellos sucesos o hechos que poseen contenido de orden jurídico y de allí interesan al derecho. Todo ello exige la necesidad de una toma de posición a fin de poder explicar cuándo y por qué un acontecimiento (humano o natural) posee dicha virtualidad, es decir, ser un "hecho jurídico". Para dar respuesta a ese interrogante existen dos teorías opuestas y algunas otras opiniones de menor importancia. En el presente, se ha tratado de definir y aclarar los contornos de ambas tesis. Una primera idea sostiene que el hecho jurídico es aquel que posee por sí mismo el carácter y la potencialidad para lograr el objetivo, es decir, el efecto legal. Ello lleva a calificarlo como elemento causal suficiente de conexión lógica que le permite lograr el efecto legal, siendo por ello una cualidad del propio objeto. Esta tesis se denomina: "tradicional” o "causalista". La segunda teoría, la cual es seguida por la mayoría de los juristas italianos y tiene mucha y buena difusión en la doctrina moderna, entiende que los hechos jurídicos por sí mismos no poseen ninguna virtud especial, sino que su carácter de legales o jurídicos se da en razón de su inclusión como presupuesto en la ley. Todo lo cual los juristas italianos han denominado fattispecie, o fenómeno también conocido como "presupuesto fáctico normativo". Cuando una norma o ley entiende que para que se produzca su consecuencia de derecho es necesario el cumplimiento de uno o más hechos, dichos sucesos pasan a tener la categoría de jurídicos. Por ejemplo, el nacimiento o la muerte de las personas resultan hechos naturales, pero en la mayoría de las legislaciones a lo primero le dan el efecto de tener capacidad de derecho para adquirir; y a lo segundo, que van a transmitir el patrimonio a sus herederos. 
También se han considerado otros aspectos, especialmente las clasificaciones de los hechos jurídicos, siendo la más importante la que lleva diferenciar a los hechos naturales de los hechos humanos. Estos últimos distinguidos por la intervención del hombre, en sentido general, que ante la manifestación de voluntad puede llegar a concretar lo que simplemente se denominan "actos jurídicos" o "negocios jurídicos".

Palabras clave: hechos jurídicos, naturaleza jurídica, presupuesto normativo, clases, efectos.

\title{
Legal Acts
}

\begin{abstract}
This study is about "legal acts", which is a division of "the general aspects of private law. Most of the Civil Codes in the 20th and 21st centuries which include these general aspects, dedicate several of their articles to rule on said matter and determine in this way their nature, requirements and effects .

An example of all this are the Civil Codes in Germany (BGB), Brazil, Mexico, Switzerland among other countries. The new Civil and Commercial Code in force in Argentina since August 1st, 2015 deals with this matter in Book I, Title V, Chapter I (articles 257 to 264).

Acts are external events within the social reality which have the power to alter or modify the surrounding environment. In this context, their analysis and study only apply to those actions or facts of a juridical nature and are therefore of interest to the law. All this makes it necessary to take a stand in order to explain when and why an event either natural o human is to be considered a "legal act". To give an answer to this question, there are two opposed theories on the subject and some other irrelevant opinions. In this present, it has been intended to define and clarify the main points of both theories. One idea sustains that a legal act is the one which has in itself the character and the ability to achieve a goal, that is, the legal effect. This leads to defining it as the causal event of logical connection making it possible to get said legal effect then becoming a quality of the object itself. This theory is called "traditional" or "causative". The second theory, supported by most of the Italian lawmakers and well spread in the modern doctrine considers that the legal acts themselves do not have a particular virtue but that their legal or juridical character is given by the fact that they are presupposed to have fulfilled all statutory requirements. All this has been called fattispecie or "regulating factual presuppositions" by the Italian lawmakers.

When a rule or law understands that to have a legal consequence it is necessary to do one or more acts, said acts become legal acts. For example, the birth or the death of a person is a "natural" act, but in most legislations the person who is born has the right to acquire, and the deceased to transfer their estate to their heirs.

Other aspects have also been considered, in particular the classification of the legal acts, and the most important is the one which distinguishes natural acts from human acts which are those where a human being takes part and with the expression of their will can do what are simply called "legal acts" or "legal transactions".
\end{abstract}

Key words: legal acts, legal nature, legal presuppositions, causes, effects. 


\section{Generalidades}

Toda la temática alrededor de los hechos y su vinculación con el mundo jurídico resulta una especie de introducción y puerta de ingreso para entender mejor las realidades del derecho. La vida del hombre, la relación con otras personas y la naturaleza que lo rodea producen consecuencias de todo tipo, que asegura y prueba una especie de fuerza dinámica vital. Cuando se lo examina y estudia analíticamente, produce asombro por su particularidad y vínculo causal, pero, por otra parte, emerge como algo normal, cotidiano y corriente, por y ante los elementos culturales que posee el ser humano apoyados en la experiencia acumulada (Albaladejo, 1958, pp. 5 y ss.; Boffi Boggero, 1955, p. 57; Compagnucci de Caso, 1992, p. 1; Coviello, 1938, p. 333; De Ruggiero, 1931, p. 244; Salvat y López Olaciregui, 1964, p. 163). ${ }^{1}$

Todo el fenómeno puede ser observado desde diferentes ángulos, como la filosofía, la sociología, la psicología, la antropología o el derecho. En este caso, la visión es estrictamente jurídica, pues resulta el objetivo de estudio y desarro1lo, es decir, solamente interesan aquellos fenómenos fácticos que se nutren y completan de juridicidad. Tal como bien lo afirma Francesco Messineo (1954, p. 321), en la doctrina italiana son los acontecimientos o aquellas situaciones o estados que modifican la realidad jurídica o producen un efecto de esa clase, de allí su relevancia para el derecho. Al respecto, agrega el egregio jurista español don José Castán Tobeñas (1978, p. 646) que los hechos jurídicos son sucesos o fenómenos que acaecen en la realidad (Trabucchi, 1967, p. 133).

El profesor Ruiz Serramalera (1979, pp. 11 y ss.) concreta una serie de reflexiones dignas de tener en consideración. Entiende que en la vida del hombre es posible hallar un sinnúmero de situaciones a veces provocadas por una actuación consciente y voluntaria, o bien se generan espontáneamente y sin intervención de su voluntad. De cada una de esas situaciones o estados de hecho puede derivar una serie de consecuencias que son imputadas o afectan al individuo de forma que, en la posición en la que se encuentra, influyen de una manera u otra en su existencia o en la posibilidad de conseguir cualquier resultado concreto (Candián, 1961, p. 79; Llambías, 1975, p. 251, Spota 1967, p. 42).

De allí la relevancia de los hechos y su repercusión cuando tienen esa cualidad; de allí aparece con toda vigencia el principio romano del ex facto oritur ius, por aquello de que "sin hechos no hay derecho". Es importante señalar

1 Pugliatti (1996) brinda una síntesis precisa del fenómeno, dice: "Fatto giuridico e dunque, qualsiasi situazione del mondo del'essere prevista dal diritto come causa di effetti giuridici” (p. 3). 
que siempre es necesaria la figura del hombre en su sentido genérico, ya bien concretando los hechos o bien cuando esas circunstancias vienen a reflejarse en la órbita y esfera de los intereses que lo rodean (Arauz Castex, 1974, p. 152; Borda, 1976, p. 69; Cifuentes, 1991, p. 8; Morello, 1964, p. 13; Rivera, 1995, p. 450; Tobías, 2018, pp. 181 y ss.). ${ }^{2}$

La distinción que hacen algunos autores entre los simples hechos y los hechos jurídicos es importante, pero tiene en sí mismo un sentido relativo y no es posible afirmar que se trate de una diferenciación esencial, ya que los primeros tienen el significado de acontecimientos estrictamente fácticos que alteran la realidad, y los segundos se hallan en la órbita de lo jurídico, es decir, atrapados por el derecho. El profesor Roberto H. Brebbia (1979, p. 12) -a quien recuerdo con gran afecto, no solo por su relevante jerarquía jurídica e intelectual, sino por haber sido un hombre de bien, que me distinguiera con su amistad- efectúa la distinción indicada y con toda certeza ubica al elemento jurídico como presupuesto de una norma que, por su carácter generalizador, describe los hechos cuyas consecuencias regula; por su parte, el simple hecho como efecto de la realidad circundante tiene el efecto de concretar las consecuencias jurídicas previstas (Von Thur, 1947, pp. 3 y ss.).

Por su parte, los relevantes juristas italianos Emilio Betti (1959, pp. 3 y ss.) y Salvatore Pugliatti (1988, pp. 1 y ss.) efectúan una categorización importante entre los hechos según la diversa estructura que tengan como elemento material; por un lado, la categoría del hecho jurídico natural (fatti giuridici naturale) o tomado en sentido estricto (in senso stretto) y, por la otra, la de los hechos jurídicos del hombre en sentido amplio (fatti giuridici in senso lato).

Para el primero de los supuestos, entienden que se trata de situaciones en las que el derecho considera al evento natural como una situación en la que se prescinde de la voluntad humana y solamente se toman en cuenta las fuerzas naturales. Dan como ejemplos: la plantación, la siembra y la separación de frutos, a los que es posible agregar la inundación, el terremoto, la lluvia, la muerte, el nacimiento, etc. En estos casos, el derecho solamente queda limitado a cualificar el hecho prescindiendo de su valoración. En cambio, a los hechos jurídicos en sentido amplio (senso lato), el orden jurídico les da una relevante particularización ante la voluntad del agente. Así, los ejemplos del incendio o la inundación pueden ser una derivación de la actividad del hombre y constituir

2 Es relevante la nota de Vélez al artículo 896, que en uno de su párrafos dice: “[...] La función de los hechos en la jurisprudencia es una función eficiente [...]”, y agrega "[...] no hay derecho que no provenga de un hecho [...]". 
un delito, o estar previstos como riesgo en un contrato de seguro y, con ello, agregárseles jurisdicidad (Cariota, 1956, p. 3; Galgano, 1988, pp. 1 y ss.; Orgaz, 1963, pp. 9 y ss.; Tobías, 2018, pp. 176 y ss.; Torrente y Schlesinger, 1999, p. 185; Zatti y Colussi, 2001, pp. 97 y ss.).

La observación de los distinguidos autores es digna de tenerse en cuenta y difundir. Por un lado, el hecho en sí propio alejado de la voluntad o intencionalidad del ser humano, por el otro, dándosele un sentido amplio que va a tener diferente cualificación por la intervención de la voluntad de un sujeto. Ello produce diferentes efectos que la ley va a indicar.

A modo de síntesis, es posible señalar que el "hecho jurídico" es una cualidad de ciertos hechos cuyos efectos van a surgir con posterioridad y tendrán derivaciones para el derecho. Barbero (1967, p. 332) explica que en el aspecto físico no hay proporción alguna entre el poseer durante veinte años una cosa y, por razones jurídicas (usucapio), llegar a ser propietario; o dar a otro un puñetazo en la cara y tener que pagar una indemnización por los daños causados; o, agrego, entre la muerte de una persona y el reclamo de los herederos a la adquisición derivativa de los bienes que le pertenecían al causante, etc. (Albaladejo, 1958 , p. 6). ${ }^{3}$

Tal como se podrá ver, siempre resulta necesaria la vinculación entre el fenómeno fáctico y el orden normativo, cuestión sobre la que insisto y pecaré en la iteración, pero más adelante.

\section{La legislación. Código Civil anterior}

El Código Civil que en la Argentina tuvo vigencia hasta el 1 de agosto del 2015 se ocupó de regular en forma específica y con detalle todo lo vinculado al tema en tratamiento. Lo hizo en el Libro II, Sección II, que tituló "De los hechos y actos jurídicos que producen la adquisición, modificación, transferencia o extinción de los derechos y obligaciones”. En el primero de los Títulos, lo hizo específicamente sobre "Los hechos" (artículos 896 y ss.).

La fuente en la que se inspiró el Codificador nacional fue la obra de Freitas (Esboço), quien en el Libro I (Parte general) trató de "Los hechos" en los artículos 431 a 816 y legisló sobre los hechos voluntarios, los actos jurídicos y los

3 Flume (1998) desarrolla con erudición la temática sobre la "autonomía de la voluntad” y para esa ocasión afirma: "[...] son consecuencias jurídicas legales aquellas que se producen en virtud de la ley, en cuando la ley determina esas consecuencias valorando jurídicamente relaciones y acontecimientos, en especial los actos humanos [...] (p. 25)”. 
actos ilícitos. A su vez, el autor brasileño había seguido lo preceptuado en el "Landrecht" prusiano, y fundamentalmente en la obra de los pandectistas alemanes, en la cual sobresalía el pensamiento de Savigny (Alsina Atienza, 1955a; Borda, 1975, p. 69; Llambías, 1975, p. 251; Rivera, 1995, p. 450; Salvat y López Olaciregui, 1964, p. 165; Spota, 1967, p. 43).

Lo cierto es que Vélez Sarsfield, con el método empleado, produjo una innovación adelantándose a la época, ya que en los códigos civiles del siglo XIX - la mayoría de ellos inspirados en el Code francés de 1804- no habían tratado a los hechos y actos jurídicos como elementos conceptuales generales y separados, sino que a esta problemática se la legisló como unida a los contratos y a los testamentos. Ahora bien, puede señalarse como un pequeño demérito critico que, en el Código Civil argentino, la regulación se hizo en el Libro II referido a los "Derechos personales", y no como debió haber sido en una "parte general". Este último sistema aparece utilizado en el Código Civil alemán de 1900 (BGB) y en el mexicano, suizo, portugués y muchos otros del siglo XX (Arauz Castex, 1965, p. 152; Compagnucci de Caso, 1992, p. 7; Cifuentes, 1991, pp. 8-9; Prieto Molinero, 2014, p. 579; Rivera, 1995, p. 450). ${ }^{4}$

En cuanto al régimen del Código Civil derogado, el artículo 896 inicia la Sección 2 y define a los hechos jurídicos como: "[...] todos los acontecimientos susceptibles de producir alguna adquisición, modificación, transferencia o extinción de derechos u obligaciones". Este concepto ha sido analizado desde diferentes puntos de vista, por un lado que se considera que los acontecimientos modifican causalmente al mundo exterior e interesan al derecho cuando producen efectos a los que la norma toma en consideración.

A esa idea general se le suma la opinión de Henoch Aguiar (1950), quien fuera un distinguido profesor de la Universidad de Córdoba y que en su difundida obra sostuvo que cuando el artículo 896 habla de "susceptibles" está indicando que el hecho es jurídico cuando tiene la capacidad y aptitud suficiente -ya sea potencial o eventual- para producir efectos legales. ${ }^{5}$

Esa tesis recibió algunas observaciones críticas de otros autores. Así, por ejemplo, Rivera (1995) entiende que si los hechos jurídicos fueran todos los acontecimientos en su producción efectiva e in concreto, no existirían otros hechos fuera de la enumeración. O la importante opinión de Arauz Castex (1965,

4 Savigni (1878/1879) consideraba que los hechos jurídicos son acontecimientos "[...] en virtud de los cuales las relaciones de derecho nacen o terminan [...]" (p. 142).

5 Coincide con esa idea Llambías (1975) y al respecto dice: "El legislador con buen criterio, ha preferido seguir lo que Aguiar denomina una política de justificación preventiva [...]” (p. 251). 
pp. 152 y ss.) al señalar como ejemplo que el que ejercita el "tiro al blanco" podría indicarse como un hecho jurídico, pues eventualmente podría herir a alguien y cometer el delito de lesiones. O, como afirma Llambías (1975), que con esa idea Vélez Sarsfield aplica una especie de justicia de prevención anticipada (Arauz Castex, 1965, pp. 152 y ss.; Bueres, 1998b, p. 382; Orgaz, 1963, pp. 14 y ss.; Rivera, 1995, p. 452).

En virtud de lo adelantado, siempre se juzgó que esos acontecimientos se nutren de juridicidad cuando se brinda una especie de nexo entre el presupuesto fáctico y la previsión normativa, que lleva a la producción del fenómeno jurídico; aunque, como ya lo señalé, existe en nuestra doctrina tradicional una tendencia a considerar los hechos jurídicos como elementos "susceptibles" de por sí y, de manera causal, a producir los efectos consiguientes. Tal como enseña Bueres (1998b), con envidiable precisión y excelsa pluma,

\begin{abstract}
[...] Se aduce que el Codificador entendió que el hecho es el que posee energía para producir el efecto del derecho con menosprecio de la norma (terreno éste en el cual los autores no pisan firme y no siempre son consecuentes). Y de otra parte no es imprescindible que el acontecimiento produzca inexorablemente el efecto [...]. (p. 382)
\end{abstract}

También la definición del artículo 896 del viejo Código recibió otras observaciones en consideración a sus efectos. Cuando en los párrafos finales dice que puede producir la consecuencia de adquirir, modificar, transferir o extinguir "derechos y obligaciones", produce una consecuencia limitada que no es certera ni real, ya que deja fuera a los derechos subjetivos, contemplando solamente aspectos patrimoniales. Por ello, Brebbia (1979) señala con toda razón que al término "derecho y obligaciones" debe asignársele un sentido amplio o lato, "[...] que comprende no solo derechos subjetivos y de las obligaciones, sino también potestades que no son derechos subjetivos, y también deberes que a su vez no integran a las obligaciones [...]" (p. 23) (Compagnucci de Caso, 1980b, p. 2101; Rivera, 1995, p. 452; Tobías, 2018, p. 174).

6 Brebbia (1979, p. 23) aclara que entre los derechos subjetivos, se hallan también los in fieri, o los conocidos como "intereses legítimos", y las "expectativas de derecho", como situaciones intermedias que aún no completaron los elementos para llegar a configurarse como "derechos subjetivos plenos". 


\section{El nuevo régimen del Código Civil y Comercial}

En el nuevo Código Civil y Comercial que entró en vigencia el 1 de agosto de 2015, el hecho jurídico aparece definido en el artículo 257 que inicia el Título IV, del Libro Primero, Capítulo I y en el título general de "Hechos y actos jurídicos". El artículo 257 expresa lo siguiente: "El hecho jurídico es el acontecimiento que, conforme al ordenamiento jurídico, produce el nacimiento, modificación o extinción de relaciones o situaciones jurídicas”.

En la comparación con el texto del Código Civil anterior, pueden observarse algunas diferencias que separan el contenido conceptual de ambos. El primero y más importante es el que diferencia al hecho. Mientras que antes podía sostenerse que era un elemento fáctico que contenía en sí la posibilidad de producir el efecto jurídico, el nuevo Código vincula al hecho subsumido en la norma, es decir, como elemento con sustrato allí previsto (Compagnucci y Moreno, 2016, p. 115; Prieto Molinero, 2014, p. 578; Tobías, 2016, p. 135).

Los autores han tomado en cuenta este esencial distingo. Así, Prieto Molinero (2014) sostiene:

[...] lo que hacen las normas del ordenamiento es un juicio hipotético donde al darse A el resultado será B. O lo que es lo mismo de coincidir la realidad con una determinada descripción prevista de antemano en la norma el ordenamiento atribuirá un determinado efecto. (p. 584)

Esta cuestión, muy importante, por cierto. La trataré más adelante de modo más específico.

A más de lo dicho, otra diferenciación surge de los efectos que pueden llegar a producir los hechos jurídicos. Algunos efectúan la primera de las distinciones entre aquello del artículo 896 de "susceptibles de producir" por la expresión verbal de "producen" (Llambías, 1975, p. 251; Mayo, 198, p. 398; Orgaz, 1963, p. 11; Salvat y Romero del Prado, 1954, p. 171). ${ }^{8}$

Al respeto, el profesor Tobías (2018) señala que sobre lo previsto en el artículo 896 se había indicado que dicha expresión tenía como sentido aclarar que

7 Prieto Molinero (2014) amplía bien la síntesis del texto añadiendo: "De coincidir la realidad con una determinada descripción prevista de antemano en la norma el ordenamiento atribuirá un determinado efecto" (p. 584).

8 El anotador de la obra de Salvat aclara: "[...] Se ha criticado la definición del artículo 896, fuera de señalarse la impropiedad de que como tal, la contenga porque en otras oportunidades también lo hace porque ello debe quedar relegado a la doctrina, en cuando emplea la palabra "susceptibles" con la acepción de "capaces" (Salvat y Romero del Prado, 1954, p. 171). 
la posibilidad de producción del efecto se daba ante la presencia del hecho en la norma jurídica. Es decir que lo indicado en el viejo Código podía entenderse como suponiendo la presencia del presupuesto fáctico normativo. ${ }^{9}$

Quizá, la más trascendente diferencia está en las consecuencias previstas. Mientras que en la normativa anterior apuntaba al nacimiento, modificación, transferencia o extinción de "derechos u obligaciones", el nuevo texto indica que dichos efectos lo son sobre "situaciones o relaciones jurídicas". A mi juicio, se trata de un cambio cualitativo y, por ello, de mayor entidad abarcativa. Mientras que antes quedaba limitado a los derechos y obligaciones, ahora se llega a todas las relaciones jurídicas y también a las denominadas "situaciones jurídicas".

Ello me permite aclarar -sin desconocer que se han brindado diferentes teoríasque la "relación jurídica" es "una vinculación que establece el derecho objetivo que se da entre personas y atribuye a una un poder y a otra un vínculo correlativo", mientras que la "situación jurídica" se aparta del concepto anterior, pues consiste en el efecto que puede producir un hecho jurídico en la creación, modificación o extinción de una posición jurídica para un sujeto, que resulta desconectada de las demás. Se dan como ejemplos: el nacimiento, la muerte o el grado de parentesco (Betti, 1959, p. 552; Castán Tobeñas, 1978, p. 12; Compagnucci de Caso, 2001, pp. 32 y ss.; Galgano, 1992, p. 35; Messineo, 1954, p. 5; Rivera, 1995, p. 276).

\section{Naturaleza de los hechos jurídicos}

Entre las teorías que disputan la explicación de la esencia o naturaleza de los hechos jurídicos, se anotan dos ideas principales y algunas derivaciones. Una, muy difundida que algunos autores denominan "tradicional", y que es posible cualificar como "causalista", y otra que viene en franca oposición, que llamaremos teoría "preceptiva", equivalente a la muy difundida fattispecie (concepto ingresado por la doctrina italiana) o el tatbestand de los juristas alemanes. Todas se ocupan de explicar qué significan los hechos en vinculación con el derecho y cómo se produce su incidencia y efectos en la vida, como también la razón, si es que la hay, para que sean receptados y previstos como tales (Alsina Atienza, 1955a; Cifuentes, 1991, p. 8; Machado, 1898, p. 113)..$^{10}$

9 Tobías (2018, p. 179) aclara que para autores tales como Cifuentes (1991) y Compagnucci de Caso (2016) -en una cita propia de su gentileza habitual-,cuando el artículo 896 agregaba la expresión "susceptibles de producir" quería significar que el efecto que la norma adscribe al antecedente solo se realizará si existe un acontecimiento real subsumido en el precepto jurídico.

10 Llambías (1975) afirma: "En suma el hecho jurídico se caracteriza por poseer la virtualidad de 


\section{Tesis tradicional}

Esta corriente de opinión que tiene mucha y buena difusión entre los juristas locales toma en consideración al hecho en sí mismo para determinar cuándo y cómo pasa a integrar la categoría de jurídico. Tiene una conexidad inmediata con la causalidad material y la jurídica y, para ello, primero analiza el hecho y luego sus consecuencias. ${ }^{11}$

El hecho pasa a ser una especie de condición lógica sine qua non para la producción de efectos que interesan al derecho. Es imprescindible la existencia de un nexo de causalidad natural de lo fáctico que pueda producir el efecto jurídico. Claro está que resulta importante aclarar que los hechos por su sola sustancia no pueden lograr la consecuencia en el mundo del derecho, pues están siempre en el cuerpo de la ley, pero ello solo resulta una especie de antecedente que da eficacia a la consecuencia, ya que, como bien enseña el profesor Tobías (2018)

En el mismo orden de ideas no puede dejar de admitirse sin embargo que los hechos, fenómenos temporales, no producen por sí mismos efectos jurídicos, se agrega entonces que es la norma la que atribuye a los hechos el ser productores de efectos [...]. (p. 183) 12

Considero que para esta postura, tal como ya lo observé, lo transcendente y relevante es el hecho, no su presupuesto, el que prevalece para concretar las consecuencias que llevan hacia el derecho. Es una relación lógica que mediante un proceso causal, y con un estudio o análisis posterior o ex post facto, dará el resultado de poder ser cualificado como "jurídico" (Aguiar, 1950, p. 14; Brebbia, 1979, p. 451; Prieto Molinero, 2014, p. 580).

El caso de la muerte (como ejemplo con alto grado de sensibilidad y tragedia, como diría Unamuno) generalmente produce como consecuencia jurídica

producir una consecuencia de derecho, aunque aun esa consecuencia no haya ocurrido o pueda resultar frustrada" (p. 252).

11 Salvat y Romero del Prado (1954) sostienen: "Esta condición (apta para producir efectos) es lo que constituye el carácter esencial de los hechos jurídicos susceptibles de influir en los derechos y obligaciones, ya sea para adquirirlos, ya para modificarlos, transmitirlos, o extinguirlos" (p. 170). Analizo brevemente esta tesis en Compagnucci de Caso (1992, p. 3).

12 En el análisis de lo previsto en el artículo 896 del Código anterior, Orgaz (1963) enseña con notoria sabiduría: "La posición empirista, al no advertir el carácter imputativo de las reglas jurídicas, aplica al derecho la relación causal que es propia del reino de la naturaleza, y así vincula al supuesto de hecho a la consecuencia de un modo material y físico, de modo que el supuesto actúa en la producción o modificación de la consecuencia, por el mismo sin intervención efectiva de la norma” (p. 11). 
la sucesión del patrimonio hacia otras personas. Ese es el hecho y su efecto jurídico; pero si el legislador dispusiera que tal efecto no se produce porque no hay más herencias hacia nadie, incluido el ambicioso Fisco, el hecho quedará como suceso natural y nada más.

Esta tesis ha recibido fundadas críticas adversas, las cuales se dirigen a replicar tanto el sentido que se le ha conferido al vocablo "susceptible" como al que recientemente se hizo referencia, es decir que los hechos son jurídicos en la media en la que se encuentren previstos en la norma, pues, de lo contrario, nunca tendrán incidencia causal por sí mismos, es decir, no pueden ser jurídicos per se. ${ }^{13}$

A ello se ha agregado la relevante distinción entre la causalidad natural y la causalidad normativa, ya que la primera se apoya en cuestiones físicas o sociales que explican sus resultados, o, como dice Orgaz (1963),

la diferencia esencial que existe entre la causalidad física o natural y la causalidad jurídica es que la primera establece una relación de cómo suceden las cosas realmente, mientras que la segunda establece cómo deben ocurrir de acuerdo con las prescripciones de la ley. Este deber ser es propio de toda norma [...]. (pp. 1 y ss. $)^{14}$

Al respecto, y como ejemplo de causalidad física o natural, es posible señalar que el agua, a determinada presión y con más de 100 grados de temperatura, comienza a transformarse de elemento líquido a gaseoso, lo que permite sostener una regla de causalidad. En cambio, la denominada "causalidad normativa" se encuentra establecida en la ley y a veces no responde a los designios de la causalidad física, pues la contradice o dicta supuestos cercanos a la ficción. En algunos casos particulares, la afirmativa ofrece notoriedad; por ejemplo, cuando por el hecho de una ausencia prolongada de una persona se puede solicitar la declaración del fallecimiento, o en los casos que se ordenan efectos retroactivos, o cuando resulta de aplicación la teoría de la apariencia incoincidente con la realidad, etc. (Boffi Boggero, 1980; Rivera, 1995, p. 453). ${ }^{15}$

13 Gran parte de los autores que se han ocupado en el estudio del tema han puesto el acento y la crítica en lo que se indica en el texto: Borda (2008, p. 69), Bueres (1998a, p. 381) y Orgaz (1963, p. 14).

14 Véanse Alsina Atienza (1995a); Bueres (1998a, p. 384); Compagnucci de Caso (2016, p. 378); Puig Brutau (1978, p. 827); Tobías (2018, p. 185).

15 Brebbia (1979) afirma: "La causalidad normativa se rige por sus propias reglas que pueden o no coincidir con el ordenamiento natural o de los hechos sociales, atribuyendo a veces por ejemplo relevancia jurídica a acontecimientos que no son reales" (p. 41). 


\section{Teoría preceptiva (fattispecie)}

Es la que hoy prevalece entre los autores y explica satisfactoriamente la naturaleza de los hechos jurídicos. A modo de síntesis, es posible afirmar que si bien la ley tiene un contenido de abstracción, ya que generaliza los diversos casos que enfrenta y plantea, prevé como presupuesto de hipótesis diversos hechos que contempla para su concreción. De allí que ello lleve a considerar a los hechos jurídicos como "[...] aquellos a los que el derecho atribuye trascendencia jurídica para cambiar las situaciones preexistentes a ellos y configurar situaciones nuevas a las que corresponden nuevas calificaciones jurídicas" (Betti, 1959, p. 5) (Barbero, 1967, p. 332; Cariota Ferrara, 1956, p. 111; Pugliatti, 1996, pp. 3 y ss.; Trabucchi, 1967, pp. 133 y ss.). ${ }^{16}$

También se ha señalado que un hecho jurídico es, por tanto, cualquier situación en el mundo prevista por el derecho como causa de efectos jurídicos, en la que se incluyen hechos naturales y humanos en una unidad integradora, sin perjuicio de su distingo en la génesis (Galgano, 1988, pp. 321 y ss.; Orgaz, 1963, p. 12; Sconamiglio, 1954, p. 331). ${ }^{17}$

Por su parte, Albaladejo (1958), entre los más conspicuos civilistas españoles, enseña que hecho jurídico es

[...] todo acontecimiento o estado -en general todo suceso o falta del mismo (ya que también hay hechos negativos)- el que por su sola realización, o juntamente con otros, liga el Derecho objetivo, la producción de un efecto, que es efecto jurídico precisamente en cuanto dispuesto por ese derecho objetivo [...]. (p. 6 6 ${ }^{18}$

Así también lo acepta la definición del artículo 257 del Código Civil y Comercial, cuando inicia su descripción con: "El hecho jurídico es el acontecimiento que, conforme al ordenamiento jurídico [...]”, lo cual importa un reconocimiento expreso a la tesis que ubica a la causa y efecto de estos hechos a la recepción normativa (Compagnucci de Caso y Moreno, 2016, p. 117; Prieto Molinero, 2014, p. 580). ${ }^{19}$

16 Zatti y Colussi (2001) lo definen así: "Ogni fatto al quale una norma giuridica collega un qualsiasi effetto" (p. 97 y ss.).

17 Zatti y Colussi (2001). Torrente y Schlesinger (1999, p. 184) titulan "La fattispecie".

18 Véanse Castán Tobeñas (1978, p. 642); Espín Canovas (1977, p. 424); Lacruz Berdejo (1984, p. 133); Ruiz Serramalera (1979, p. 14); Santos Briz (1978, p. 557).

19 Tobías (2016) enseña que: "[...] es posible afirmar que el agregado (artículo 257 del C.C. y com.) destaca la relevancia de las normas en el advenimiento de los efectos jurídicos de los hechos [...]" (p. 139). 
Como se puede observar, es la misma normativa la que prevé y adelanta cuáles son los efectos ante la producción de un hecho o varios de ellos, hechos que se encuentran subsumidos en la ley.

Este fenómeno tiene fama y su denominación como fattispecie le corresponde en plena propiedad a la doctrina italiana, y resulta ampliamente aceptada y reconocida. Fattispecie significa "figura del hecho" y deriva del latín del Medioevo fatis species, que, como enseña Betti (1959, pp. 4 y ss.), resulta una cualificación preferible a la del "hecho jurídico", porque fattispecie significa tanto el hecho propiamente dicho como el estado de hecho y "derecho sobre el que el hecho incide" (Pugiatti, 1996, p. 320).

En muchos casos, la ley prevé más de un elemento fáctico para determinar su resultado. Sirva como ejemplo la "prescripción adquisitiva", o comúnmente llamada como su antecedente romano usucapio; para que produzca el efecto de la adquisición originaria de la propiedad se exigen variedad de hechos: la posesión pública y pacífica de un bien, el animus rem sibi habendi, el tiempo que se determina, etc. Es decir, la adición de todos esos simples hechos podrá producir la consecuencia legal. ${ }^{20}$

Es lo que los alemanes denominan tatbestand, figura tomada de los penalistas con una cierta equivalencia a lo señalado por la doctrina italiana. En ese sentido, entienden que el conjunto de los hechos resultan el factum de la norma, que, cuando se producen, van a modificar el mundo exterior. Se dan como ejemplos: el nacimiento, la renuncia, la muerte, lesiones causadas a una persona, etc. En esa dirección, Lehmann (1956) sostiene que el supuesto de hecho (tatbestand) "[...] es el conjunto de requisitos precisos para que se produzca el efecto jurídico, nacimiento, extinción o modificación de una relación jurídica [...]” (p. 195) (Von Tuhr, 1947, pp. 3 y ss.).

En cuanto a la fattispecie, y como cuestión para tener en cuenta, Trabucchi (1967) enseña que dicha categorización se integra con ciertos elementos que la ley reconoce y les da un carácter abstracto para que sean presupuestos de una modificación jurídica, a la par que el presupuesto concreto se da en el propio y simple hecho de que concurre para que se produzca el efecto. Y a estos hechos concretos -en el caso de una compraventa- se los categoriza como "títulos", que en el supuesto ejemplificado van a justificar y a fundamentar el derecho de propiedad y el de percibir el precio (Trabucchi, 1967, p. 134).

Ahora bien, para completar el punto y a modo de resumen es posible sos-

20 Con respecto a lo previsto en los artículos 1897 a 1907 del Código Civil y Comercial, véanse Mariani de Vidal (1995); Moisset de Espanés (1998); Puerta de Chacón (2015). 
tener que la tesis de la fattispecie satisface los requerimientos de la razón para mostrar la esencia de los hechos jurídicos. Tal como lo desarrolla Emilio Betti (1959) en excelsa fórmula

[...] la norma jurídica considerada en su estructura lógica consta de una previsión y de una disposición correlativa. Ella prevé en abstracto y en general hipótesis de hecho clasificadas por tipos y orientados así en las directrices de una valoración jurídica, hipótesis que en términos técnicos se denomina fattispecie. (pp. 5 y ss.) ${ }^{21}$

\section{Otras tesis intermedias}

Las ideas no se agotan en las dos posturas expuestas, pues hay otras tesis que podrían cualificar como "intermedias", en las que aparecen diferentes factores para explicar la esencia de los hechos jurídicos.

Una de ellas es la que desarrolla el profesor Albaladejo (1958) en la doctrina española. Al respecto, señala que, además de lo ya indicado, hay autores que entienden que tanto la norma como el hecho resultan causas del efecto jurídico. Y agrega que en su personal opinión, “[...] ambos norma y hecho -unidos- son una especie de concausa de las consecuencias [...]" (p. 10).22

También surgen ideas alrededor de la causa para atribuirla a uno u otro en forma de un balanceo valorativo, incluyendo este elemento como anterior o situación jurídica previa que viene a alterar al hecho al que la norma fuerza de modificación en determinados y precisos casos, aun cuando su concurrencia sea ocasional con otros hechos. ${ }^{23}$

El tema se llena de complejidades, pues los hechos pueden ingresar por concurrencia causal o meramente ocasional, pero en ambos casos no renuncian a tener carácter de jurídicos. Es buen ejemplo el "granizado en un campo", que generalmente acompaña a una lluvia copiosa o torrencial: en principio es un simple elemento fáctico, pero si el dueño de la tierra arrasada había contratado un seguro por dicho riesgo, el mentado "granizo" pasa a tener categoría de hecho jurídico. ${ }^{24}$

21 Véanse Barbero (1967, p. 332); Galgano (1988, pp. 1 y ss.); Zatti y Colussi (2001, pp. 98 y ss.).

22 Von Tuhr (1947, p. 5) explica, siguiendo la postura mayoritaria, que entre el hecho y la norma existe una relación de causalidad que no descansa en el orden natural, sino en la voluntad de la ley.

23 Tobías (2018) desarrolla todas estas ideas con erudición y una envidiable precisión. Barbero (1967) concluye el acápite afirmando: "La fuerza jurídica está en la norma, en el hecho está solamente la razón en virtud del cual la norma despliega su precepto [...]" (p. 333).

24 Orgaz (1963), en apoyo a la teoría normativa, dice: "El derecho escoge y combina libremente las par- 


\section{Clasificación de los hechos jurídicos}

Las clasificaciones de los hechos jurídicos son variadas y, para ello, se utilizan diversos criterios. Aquí solo trataré aquellas que se vinculen y posean efectos prácticos y concretos, y de manera sucinta para no agobiar. De ese modo, pueden distinguirse hechos: (a) naturales y humanos; (b) simples y complejos; (c) positivos y negativos; y (d) constitutivos, modificativos y extintivos.

\subsection{Naturales y humanos}

Los hechos naturales o exteriores son aquellos que surgen de la naturaleza sin ninguna intervención de los seres humanos. Se dan como ejemplos clásicos el nacimiento, la lluvia, un terremoto, el viento huracanado, etc. Los ejemplos pueden multiplicarse por que son numerosos y, por su notoriedad y simple experiencia, no merecen mayores explicaciones. Muchos de esos factores son aptos para producir consecuencias jurídicas, de esta manera, el nacimiento con vida brinda la capacidad de derecho que se otorga al nasciturus (artículo 21 del Código Civil y Comercial), o el deterioro de las cosas que incide en el cumplimiento de algunas obligaciones (artículo 755), al igual que la avulsión (artículo 1961) o el aluvión (artículo 1959), el tiempo en su transcurrir es un requisito para alegar la usucapión (artículos 1897 y ss.) o la muerte que inexorablemente lleva a la sucesión y transmisión de los derechos y obligaciones a sus herederos (artículos 2277 y ss.) se muestran entre tantos sucesos de la vida corriente (Arauz Castex, 1965, p. 15; Borda, 1976, p. 71; Brebbia, 1979, p. 15; Cariota Ferrara, 1956, p. 5; Cifuentes, 1991, p. 17; De Ruggiero, 1931, pp. 244-245; Llambías, 1975, p. 254; Ruiz Serramalera, 1979, p. 12; Spota, 1967, p. 48).

Los aconteceres humanos tienen una mayor influencia en el derecho, pues producen superiores efectos. Es necesario diferenciar estos actos cuando son obrados voluntariamente de aquellos cualificados como involuntarios. Los primeros, decía el anterior Código Civil, son los ejecutados con "discernimiento, intención y libertad" (artículo 897), principio que se repite en el artículo 260 del Código Civil y Comercial. En el nuevo Código, la involuntariedad aparece en los casos en los que el sujeto no tiene aptitud de discernir (artículo 262)

tes de la realidad que le interesan para hacer de ellas el supuesto de hecho de una determinada consecuencia. Esta libertad del derecho muestra por sí sola que el mundo natural o real, al ser recogido por las normas jurídicas, sufre necesariamente una desintegración y un recomposición dirigidas a fines prácticos que tiene en vista la norma jurídica” (p. 12). La cita, quizá un poco extensa, muestra la profundidad de conocimientos y sapiencia del relevante jurista. 
(Boffi Boggero, 1955, p. 721; Compagnucci de Caso, 1992, p. 12; Coviello, 1938, p. 342; Ennnecerus y Niperdey, 1966, p. 9; Larenz, 1978, p. 421; Salvat y Romero del Prado, 1954, p. 158).

Es importante señalar que los hechos humanos voluntarios adquieren la jerarquía de "actos jurídicos" cuando la voluntad del sujeto se exterioriza mediante una manifestación de voluntad consciente, es decir, la jerarquía de acto jurídico se logra cuando se adicionan la voluntariedad y la conciencia. Cuando la voluntariedad no recibe una especial consideración ni es tomada en cuenta por el derecho para atribuirle efectos jurídicos, se trata de un "hecho jurídico", en cambio, es un verdadero "acto jurídico" cuando el derecho valora al hecho humano de conformidad a la voluntariedad y la conciencia que lo predetermina (Alsina Atienza, 1955b; Betti, 1959, p. 12; Brebbia, 1979, p. 65; García Amigo, 1979, p. 651; Messineo, 1954, p. 332).

A su vez, los actos voluntarios lícitos que, por los elementos señalados, producen consecuencias jurídicas son los comúnmente denominados "actos jurídicos”. Debo aclarar que la doctrina más actualizada efectúa una importante distinción entre los actos jurídicos y los negocios jurídicos. Los primeros poseen algún efecto jurídico aun cuando sus autores no lo tengan en mira, en cambio, en los "negocios jurídicos", el o los sujetos obran con la intención y el designio de que dicho efecto sea de carácter "inmediato". Cariota Ferrara (1956, p. 27) enseña que ambos son actos voluntarios, pero en los negocios esa voluntad se encuentra dirigida hacia un fin jurídico, es una voluntad del contenido y del fin de la manifestación. El otro simple "acto jurídico" es el acto humano y produce efectos sin que la voluntad se incline a dichos fines (Cifuentes, 1991, p. 28; Sconamiglio, 1969 , p. 161). ${ }^{25}$

Al respecto, Von Tuhr (1947, p. 118) realiza la siguiente calificación de los hechos humanos voluntarios: (a) son negocios jurídicos aquellos que producen un efecto jurídico inmediato modificando una situación jurídica existente; y (b) se trata de simples actos jurídicos cuando no se procura un efecto jurídico, sino un resultado de hecho que, sin embargo, la ley dota de efectos jurídicos.

Se pueden mostrar como ejemplos de los actos jurídicos no negociales: la interpelación para constituir en mora al deudor (artículo 887), el reconocimiento de una obligación (artículos 733 a 735), el acto de notificación al sujeto cedido de la transferencia del derecho entre cedente y cesionario (artículo 1620), la

25 De Castro (1985), egregio jurista considerado por sus pares españoles como "el más grande de todos los tiempos” (Diez Picazo, Vallet de Goytisolo, etc.), desarrolla magníficamente los orígenes del vocablo "negocio jurídico" y cómo se fue incorporando a la mejor doctrina española y su concepción actual. 
elección que realizan el acreedor o el deudor en la obligación alternativa (artículo 780), el hallazgo (artículo 1955), etcétera.

En el carácter de negocios jurídicos, la enumeración es mucho más simple, pues cualquier contrato ingresa en ese calificativo, también el testamento como acto unilateral. En síntesis, son todos aquellos actos voluntarios lícitos a los que las partes le adicionan la intención y la inmediatez del efecto jurídico (Albaladejo, 1958 p. 45; Betti, 1959, p. 50; Cariota Ferrara, 1956, p. 49; Cifuentes, 1991, p. 115; Compagnucci de Caso, 1992, p. 65; Galgano, 1988, p. 17; Orgaz, 1963, p. 102; Ruiz Serramalera, 1979, p. 21; Torrente y Schlesinger, 1999, p. 150).

\subsection{Simples y complejos}

Esta es una clasificación de poca difusión; se basa en la cantidad de hechos que integran el efecto jurídico, o, mejor dicho, su presupuesto normativo correspondiente. Los simples son aquellos que se integran con un solo elemento fáctico, mientras que a los complejos o compuestos se les adicionan varios de ellos, y, en muchas ocasiones, se les agregan actuaciones humanas (Albaladejo, 1958; Cifuentes, 1991; Orgaz, 1963). ${ }^{26}$

Cuando la ley exige la existencia de una serie de hechos plurales para que se logre el resultado y los efectos previstos en la norma, resulta necesario que se concreten todos. Ahora bien, puede ser que la previsión legal requiera que sean simultáneos o bien vayan acaeciendo de manera sucesiva, es decir, en momentos temporales diferentes. Al respecto, $\operatorname{Orgaz}(1963$, p. 30) señala la importancia que puede llegar a tener a los fines de determinar el tiempo en el que la consecuencia de derecho se produce, como también establecer si nace algún tipo de derecho provisional o cautelar aun cuando no se hubieran concretado la totalidad de los hechos (Brebbia, 1979, p. 24; Cifuentes, 1991, p. 27; Larenz, 1978, p. 258; Messineo, 1954, p. 27; Orgaz, 1963, p. 30).

Este tema tiene una importante y relevante cuestión vinculada a las diferentes etapas del cumplimiento de los elementos fácticos con espacios temporales, y es la que refiere al derecho subjetivo y a las denominadas "situaciones jurídicas secundarias". También merece un somero análisis cuando la ley prevé que, ante el ultimo acontecimiento, debe computarse el efecto retroactivo, es decir que la consecuencia jurídica pasa a considerarse desde el inicio del vínculo con

26 Von Tuhr (1947) aclara bien: "[...] por lo general los hechos complejos consisten en una pluralidad de hechos, porque requieren varios actos de las mismas o de distintas personas, o porque al acto debe agregarse otro acontecimiento, o porque se exige un estudio determinado en el momento del acto o del acontecimiento" (p. 15). 
el primero de los elementos fácticos. Esto último mantiene alguna conexión con el denominado "efecto retroactivo de la ley". ${ }^{27}$

Cuando se trate del proceso de hechos que se suceden unos a otros en el tiempo, resulta imprescindible que se cumpla el último para que aparezca el efecto previsto en la norma, pero, a medida que van ocurriendo, se da una especie de incertidumbre en la que las consecuencias legales se hallan pendientes. Esa integración -y según las circunstancias- pueden llevar a una mayor o menor incerteza para poder prever su producción o su frustración. El ejemplo de una obligación sometida a un plazo suspensivo, o a una condición con dicha cualidad, es clásico: si alguien se obliga a pagar a otro una suma de dinero en el término de treinta días, la expectativa del acreedor es de mayores probabilidades de cumplimiento que si dicha obligación estuviera sometida a un hecho condicional (futuro e incierto), como puede ser que un barco arribe a un puerto antes de determinada fecha, o se produzca una lluvia en un día determinado, etc. (Busso, 1957, p. 453; Cerutti de Zalocchi, 1982; Compagnucci de Caso, 1980a, p. 1548; Falzea, 1941, p. 72). ${ }^{28}$

De esa manera, es posible observar que se trata de una situación calificada por distinguidos autores (Brebbia, 1979, p. 24; Cariota Ferrara, 1956, p. 6) como "estado de pendencia". Es que al no hallarse completado el factum normativo, no es posible pensar en el efecto pleno y total. En ambos ejemplos, el acreedor está impedido de reclamar el cumplimiento de la prestación, pero ello no impide que aparezcan algunos efectos prodrómicos de un grado menor al que surge ante el cumplimiento de la totalidad de los hechos. En cuanto a los ejemplos, en ambos casos -es decir, previo al vencimiento del término o cumplimiento de la condición- el acreedor tiene derecho a solicitar medidas precautorias a fin de proteger su derecho creditorio (Betti, 1959, p. 8; Cifuentes, 1991, p. 27; Von Tuhr, 1947, p. 19).

El otro tema que concita la presencia de hechos complejos que se producen pro rata temporis es el efecto retroactivo y la extraña problemática que todo ello encierra. Como regla general, este tipo de situación jurídica siempre produce sus consecuencias, tal como ya se dijo, a partir de la concreción del último de

27 Sobre las situaciones jurídicas secundarias, véanse Compagnucci de Caso (1980b); Espín Cánovas (1977).

28 El Dr. Cazeaux (2004, p. 560) enseña con minuciosos detalles las ideas que fueron expuestas en cuanto a la naturaleza del contrato u obligación sometidos a una condición suspensiva pendiente. Ellas van desde los autores que consideran que se trata de una "simple esperanza" a aquellos que lo consideran "un derecho in fieri o in potentia", o "derecho en suspenso o eventual" o una "expectativa de derecho". 
los elementos fácticos, pero a veces la ley ordena que los efectos tengan una especie de magia jurídica y se consideren a partir del primero de los hechos sucesivos o de alguno intermedio. Dice Brebbia (1979), siguiendo a Messineo (1954) y a Santoro Pasarelli (1964): "[...] la retroactividad constituye una desviación del principio de causalidad jurídica que hace nacer los efectos con anterioridad al elemento causal, teniendo carácter excepcional" (p. 23). ${ }^{29}$

Se han brindado diferentes razones para justificar el mentado efecto retroactivo, que, demás está decir, estos casos integran situaciones excepcionales que solamente la ley aplica y generalmente vienen a proteger a determinadas personas, o bien, como indica Betti (1959), "[...] a dejar en claro que el último hecho tiene como único valor aclarar el estado de la relación jurídica existente y, de ese modo, borra la incertidumbre que pesaba sobre ella". ${ }^{30}$

\subsection{Positivos y negativos}

Como adelanto conceptual es posible afirmar que un "hecho positivo" consiste en un acontecimiento o suceso, en cambio, el negativo es siempre una forma de "omisión". Para dejar en claro esta diferenciación es importante retornar a las ideas de la relación causal, ya que en la vinculación de causalidad natural no es posible efectuar el distingo, pues nunca una omisión puede ser condición suficiente para producir la consecuencia (Castán Tobeñas, 1978, p. 647; Lehmann, 1956, p. 196). ${ }^{31}$

Siempre es necesario ubicarse en el mundo de lo jurídico para que la creación legal imponga efectos a elementos que no llegan a concretarse o revelarse.

29 (Cifuentes, 1991). Santoro Passarelli (1964, p. 113) coincide con otros autores al señalar que la retroactividad se cuenta a partir del hecho principal que tiene una fuerza causal jurídica mayor. Von Tuhr (1947, p. 19) afirma que ante la presencia de varios elementos, algunos toman el carácter de causa del resultado y otros obran solamente como condiciones.

30 El Código Civil tenía varios ejemplos de situaciones con efecto retroactivo. En el nuevo Código Civil y Comercial, algunos de esos han desaparecido; por ejemplo, con el cumplimiento de la condición, el viejo artículo 543 determinaba que, cumplida la condición, las consecuencias se trasladaban al tiempo de contraída la obligación, y ello ha cambiado. No ocurre lo mismo con el efecto de la compensación, ya que tanto el anterior artículo 818 como el actual 921, en conjunción con el artículo 924, disponen que luego de opuesta la defensa correspondiente, sus efectos se cuentan a partir de que ambas obligaciones comienzan a coexistir y se dan los requisitos para dicho efecto extintivo (Ossola, 2018).

31 De Castro (1984, p. 623) afirma que la conducta positiva es la que se manifiesta en un actuar, así como se conduce una persona con respecto a su familia, a su patrimonio, a una casa o a actos ajenos. Y la negativa es un "no hacer", como forma de mera abstención o negativa. Me permito sostener que ello lo es en el sentido material, pero no en lo que dispone a veces la ley. Véanse De Gasperi y 
Con relación a los hechos positivos, el profesor Albaladejo (1958), en sus sabias enunciaciones, da el siguiente ejemplo: "Una declaración de voluntad jurídicamente relevante es siempre para el derecho un hecho positivo, porque por la propia esencia jurídica de la cosa esta declaración consiste en un hecho, en un hacer algo jurídico, exteriorizar la voluntad [...]" (p. 15). ${ }^{32}$

También debo señalar que, a veces, la voluntad es posible que sea declarada mediante una conducta omisiva en su propio sentido material, pero para el derecho ese no actuar que se cualifica como "silencio" en ciertas ocasiones trae las mismas consecuencias que en los actos de orden positivo. Es por ello que el distinguido profesor Albaladejo (1958) señala la necesidad de "[...] No confundir la declaración de voluntad mediante una omisión en sentido material, no jurídico, con la atribución ex lege de efectos jurídicos a los que el derecho considere como una omisión (hecho negativo). En el primer ejemplo se trata de una omisión en sentido material, pero jurídicamente positivo; en el segundo que también es omisión material, que constituye un hecho jurídico negativo" (p. 15) (Carnelutti, 2003, p. 234; Castán Tobeñas, 1978, p. 647; Compagnucci de Caso, 1992, p. 18; 1994; Von Tuhr, 1947, p. 10 y 19).

Lo previsto en el artículo 2289 del Código Civil y Comercial sobre la aceptación de las herencias resulta interesante y esclarecedor. Este artículo establece que cualquier interesado puede intimar al heredero para que acepte o renuncie a la herencia que le corresponde en un término no menor a un mes ni mayor a tres meses. Si luego de la interpelación transcurre dicho plazo sin haberse realizado ninguna manifestación (hecho omisivo), la ley lo tiene por "aceptante" (Ferrer, 2016, pp. 152 y ss.; Flamma, 2014, pp. 54 y 57; Natale, 2012; Perrino, 2010; Zannoni, 2008).

En este caso, es dable ver que la adquisición de la herencia lo es por una conducta omisiva, no ex voluntate, es decir, no por una declaración de voluntad producida por el silencio, sino por el hecho negativo de haber callado. Las consecuencias de la distinción, que parecieran tener sesgos puramente académicos, tienen efectos prácticos dignos de señalarse. Verbigracia si el heredero pretendiese reclamar y demostrara que no quiso el acto, no tendría éxito en su

Morello (1964); Messineo (1954).

32 Para aclarar aún más el concepto, Orgaz (1963) enseña que cuando se trata de un hecho negativo: "[...] no se tiene en cuenta la forma en que el hecho se manifiesta sino de la omisión del hecho en sí mismo como presupuesto de una determinada consecuencia; así la falta de pago de la obligación en el tiempo debido es un hecho negativo que con otras circunstancias integra el supuesto jurídico de la ejecución forzada [...]” (p. 33). 
pedido, pues se lo considera un hecho negativo con efectos legales. Cuestión que tendría distinta solución si se tratara de un hecho positivo por omisión. ${ }^{33}$

Así, a modo de síntesis, es posible indicar que al "hecho positivo" el derecho siempre lo tiene en cuenta como un "acontecimiento", y se dan como ejemplos: una oferta de contrato, la realización de un testamento, la promesa de recompensa, un contrato de compraventa, etc. Lo mismo es posible afirmar en cuanto a ciertos casos que materialmente importan omisiones, como por ejemplo el silencio, o los supuestos de manifestaciones tácita de la voluntad cuando de la conducta obrada es posible inferir el deseo de la persona (facta concludentia), los que se califican como hechos jurídicos positivos (Cifuentes, 1991, p. 64; Orgaz, 1963, p. 15; Salvat y López Olaciregui, 1964, p. 193; Santoro Passarelli, 1964, p. 154; Santos Briz, 1978, p. 612). ${ }^{34}$

El hecho negativo se apoya en la omisión, pero por sí solo no produce efectos jurídicos; muchas veces va acompañado de otros elementos fácticos generalmente positivos. De ello un buen ejemplo lo constituye la prescripción liberatoria, que posee como requisitos la inactividad del acreedor (hecho negativo) y el transcurso del tiempo (hecho positivo). Casi lo mismo ocurre con la prescripción adquisitiva, en la que se van a brindar similares requisitos: la posesión de un objeto y el paso del tiempo requerido (hechos positivos) y la inacción del dueño (hecho negativo). ${ }^{35}$

La mayor importancia práctica de esta clasificación está en el derecho procesal, en el que se afirma que tanto los hechos positivos como los negativos son objeto necesario de prueba judicial, pero con una diferencia importante: los negativos no son susceptibles de prueba directa, sino que deben deducirse por la demostración de los hechos positivos. Al respecto, la doctrina procesalista efectúa una distinción importante entre los hechos negativos y la negativa de un hecho. De ese modo, Alsina (1956/1961, pp. 251 y ss.) enseña que solo son

33 Para esta solución, el Código Civil y Comercial ha seguido lo previsto en el artículo 2239 del Proyecto de Código Civil y Comercial de 1998; en el artículo 1005 del Código Civil español y en el artículo 1807 del de Brasil (Borda, 2008; Hidaldo García, 2015). El régimen del Código Civil español tiene una importante modificación en la Ley 15 del 2 de julio del 2015, que ahora dispone: "Cualquier interesado que acredite su interés en que el heredero acepte o repudie la herencia podrá acudir al Notario para que éste comunique al llamado que tiene un plazo de 30 días naturales para aceptar o repudiar la herencia. El Notario le indicará además que sino manifestare su voluntad en dicho plazo se entenderá aceptada pura y simplemente [...]".

34 Sobre el silencio, véanse Arauz Castex (1965); Compagnucci de Caso (1994); Coviello (1938); Llambías (1975).

35 Acerca de la prescripción, véanse Alterini (1966); Compagnucci de Caso (2009); López Herrera (2007); Moisset de Espanés (2004); Pizarro y Vallespinos (1999); Salas Acdeel (1944). 
objeto de prueba los hechos negativos, en tanto que para la negativa de un hecho basta con su alegación sin mayores exigencias (Couture, 1981, pp. 241-242; Devis Echandía, 1974, p. 507; Palacio, 2011, p. 288).

\subsection{Constitutivos, impeditivos y extintivos}

Esta clasificación es de suma importancia práctica en cuanto a la distribución y carga de la prueba procesal. Los hechos constitutivos se pueden resumir diciendo que son todos aquellos presupuestos fácticos normativos. Esa diversidad de hechos -que, como tal, ya se ha indicado-, positivos o negativos, naturales y humanos, se adicionan para la consecuencia que la ley prevé. El clásico ejemplo se brinda en la responsabilidad civil, que exige como requisitos que el sujeto haya realizado una acción humana voluntaria y antijurídica, la producción de un daño, la vinculación causal adecuada y que se sume un factor de atribución que le justifique la imputabilidad. $\mathrm{O}$, en el caso de concretarse un contrato, se exige la voluntad concorde de las partes, su capacidad, la idoneidad del objeto, la causa lícita, etc. (Brebbia, 1979, p. 40; Compagnucci de Caso, 1992, p. 21; Rivera, 1995, p. 456; Von Tuhr, 1947, p. 10). ${ }^{36}$

La persona que realiza el reclamo en la justicia no se encuentra obligada a probar todos los hechos que se suman en la norma que cita o invoca. Si bien no es posible establecer una regla, hay hechos que no exigen demostración y quedan presumidos como eficaces; otros están sujetos a la prueba correspondiente. Cuando se reclama la ejecución de una prestación prevista contractualmente -por ejemplo, si el locador demanda al inquilino y solicita la resolución en virtud de la falta de pago de los arriendos-, debe cargar con la demostración de la existencia del vínculo jurídico y la mora del demandado; no se le exige la prueba de su capacidad ni de la declaración de voluntad de ambos contratantes, y mucho menos que no se cumplieron cuotas del precio del arriendo que, por otra parte, es un hecho negativo (Albaladejo, 1958, p. 14; Barbero, 1967, p. 335; Cariota Ferrara, 1956, p. 36; Carneluti, 2003, p. 233; Morello, 1990; Orgaz, 1963, p. 33).

Los denominados "hechos impeditivos" son aquellos que van a obstruir la

36 Chiovenda (1977, p. 268), el distinguido procesalista italiano, con respecto a las condiciones de existencia de la relación, hace una distinción entre las "especificas" que exigen prueba y otras llamadas "generales o comunes" a otros negocios jurídicos. Estas últimas no integran los "hechos constitutivos”, que si bien no reclaman la prueba del actor, pueden ser objeto de una excepción alegada por el demandado. 
eficacia que pueden tener los ya vistos "hechos constitutivos". Esto aparece cuando se demuestra la falta de alguno de esos elementos fácticos, o bien en los casos en los que la ley determina una presunción iuris tantum, lo que significa que de manera provisoria o precaria da por sentada la existencia de ese factor. Por ejemplo, el artículo 1911 presume poseedor a quien ejerce un poder de hecho sobre una cosa, o bien lo previsto en el artículo 2010, que presume que el muro es medianero cuando divide dos edificios de una altura mayor a los tres metros, etc. En todos estos casos -y muchos más-, la demostración del hecho impeditivo a cargo del demandado dará por tierra con la presunción legal $(\mathrm{Ci}$ fuentes, 1991, p. 28; Orgaz, 1963, p. 34; Von Tuhr, 1947, pp. 10 y ss.).

Por último, los "hechos extintivos", tal como su denominación lo indica, son aquellos que concluyen y hacen decaer la relación jurídica invocada. Vienen a destruir algunos de los hechos integrados en la norma que van a dejar sin efecto y valor al reclamo del actor. Siempre se dijo que el pago era un buen ejemplo de hecho extintivo, pues ante el reclamo del acreedor, si el deudor demuestra el cumplimiento, la pretensión quedará trunca y sin procedencia; ${ }^{37}$ otro caso lo constituye la demostración de la compensación (artículos 921 y ss.) o algún otro medio de extinción de la relación obligacional (Brebbia, 1979, p. 34; Compagnucci de Caso, 1992, p. 23; Von Tuhr, 1947, p. 11).

Esta clasificación posee una relevante transcendencia en el onus probandi en el proceso judicial civil y comercial. Es el actor quien debe asumir la carga de los hechos constitutivos, con las limitaciones ya señaladas, en cambio, será el demandado el que tenga la obligación de demostrar los hechos impeditivos y extintivos. Es importante dejar sentado que cuando el demandado se limita a negar la procedencia por inexistencia de algunos hechos, no debe probar, salvo algunos supuestos de excepción, como la aplicación al caso del sistema de las pruebas leviores, o de la inversión de esa carga por la tesis de la dinámica probatoria, etc.; en cambio, cuando afirma la existencia de algunos hechos que, en cierta medida, la ley presume (cosa objeto del contrato que se halla fuera del comercio o vicio de la voluntad), allí la carga probatoria recae sobre el demandado que opuso las defensas (Albaladejo, 1958, p. 14; Barbero, 1967, p. 335; Brebbia, 1979, p. 34; Carnelutti, 2003, p. 267; Compagnucci de Caso, 1992, p. 23; Rivera, 1995, p. 459; Von Tuhr, 1947, p. 11). 


\section{Conclusión}

A modo de colofón, es dable señalar que toda la temática alrededor de los "hechos jurídicos" ofrece como elemento propedéutico al estudio del derecho privado una importante variedad de matices y un modo de explicar las bases y principios de estas normas. Como suele decir el profesor Guido Alpa, "Qualsiasi fatto, cio accadimento, che abbia relevancia per el diritto è denominato fatto giuridico".

Los hechos son elementos cotidianos corrientes que interesan al derecho en cuanto poseen ese carácter y pueden modificar la realidad jurídica. Su materia se revela en la expresión ex facto oritur ius, es decir que sin hechos no hay derecho.

Para revelar la naturaleza de los hechos jurídicos, dos tesis principales se disputan su preeminencia y explicación. Una de ellas, llamada "tradicional", considera que es hecho jurídico aquel que en sí mismo contiene la esencia que lo lleva a producir los efectos que contempla la ley. Para llegar a ello, se exige un detenido análisis del vínculo causal a ser realizado ex post facto.

Otra idea que la doctrina de los autores denomina como "preceptiva", y es hoy receptada por la normativa vigente, ${ }^{38}$ entiende que son hechos jurídicos aquellos a los que el derecho prevé como presupuesto normativo. Lo muy difundido en la doctrina italiana como fattispecie. Esta postura tiene un mayor número de adherentes y, a mi modesto parecer, satisface mejor su entendimiento.

En cuanto a sus clasificaciones, he tratado de sintetizarlas y, haciendo un breve estudio, incluir aquellas de mayor importancia práctica. No dejo de señalar que, en numerosos ejemplos, los presupuestos fácticos normativos aparecen adicionados y variados a fin de completar la consecuencia jurídica plena. La prescripción adquisitiva es un buen ejemplo de ello.

\section{Bibliografía}

Aguiar, H. (1950). Hechos y actos jurídicos en la doctrina y en la ley (Tomo I). Buenos Aires: Tea. Albaladejo, M. (1958). El negocio jurídico. Barcelona: Bosch.

Alsina Atienza, D. (1955a). Los hechos jurídicos. J. A., II(57), 57-62.

Alsina Atienza, D. (1955b). Los hechos voluntarios. Concepto y papel especial de la voluntad. J. A., IV(64), 62-67. 
Alsina, H. (1956/1961). Tratado de derecho teórico práctico de derecho procesal civil y comercial (Tomo II). Buenos Aires: Ediar.

Alterini, J. H. (1966). Prescripción. En Enciclopedia Juridica Omeba (Tomo XXII). Buenos Aires: Editorial Bibliográfica Argentina.

Arauz Castex, M. (1965). Derecho civil. Parte general (Tomo II). Buenos Aires: Cooperadora de Derecho.

Barbero, D. (1967). Sistema del derecho privado (Tomo I). Buenos Aires: EJEA.

Betti, E. (1959). Teoría general del negocio jurídico (2a ed.). Madrid: R.D.P.

Boffi Boggero, L. M. (1955). Hechos jurídicos. En Enciclopedia Jurídica Omeba (Tomo XIII). Buenos Aires: Editorial Bibliográfica Argentina.

Boffi Boggero, L. M. (1980). Reflexiones sobre los hechos jurídicos. La Ley, 1980-C-850, 850-859.

Borda, G. A. (1976). Tratado de derecho civil argentino. Parte general (6 $6^{\mathrm{a}}$ ed., Tomo II). Buenos Aires: Abeledo Perrot.

Borda, G. A. (2008). Tratado de derecho civil argentino. Sucesiones (9a ed., Tomo I). Buenos Aires: La Ley.

Brebbia R. H. (1979). Hechos y actos jurídicos. Comentario de los artículos 896 a 943 del Código Civil. Doctrina y Jurisprudencia (Tomo I). Buenos Aires: Editorial Astrea.

Bueres A. J. (1998a). Comentario al artículo 896. En Bueres, A. J. (Dir.), Código Civil y Comercial de la Nación y normas complementarias. Análisis doctrinal y jurisprudencial (Tomo II-B). Buenos Aires: Hammurabi.

Bueres, A. J. (1998b). Su opinión. En Bueres, A. J. (Dir.), Código Civil y Comercial de la Nación y normas complementarias. Análisis doctrinal y jurisprudencial (Tomo II-B). Buenos Aires: Hammurabi.

Busso, E. (1957). Código civil comentado (Tomo III). Buenos Aires: Ediar.

Candián, A. (1961). Instituciones de derecho privado. México: Uthea.

Cariota Ferrara, L. (1956). El negocio jurídico. Madrid: Aguilar.

Carnelutti, F. (2003). Teoría general del derecho. Granada: Comares.

Castán Tobeñas, J. (1978). Derecho civil español, común y foral (12ª ed., Tomo I, Vol. II). Madrid: Reus.

Cazeaux, P. N. y Trigo Represas, F. A. (2004). Derecho de las obligaciones (Tomo II). Buenos Aires: La Ley.

Cerutti de Zalocchi Pena, M. (1982). Modalidades de los contratos, plazo y condición. La Ley, 1982-A, 537-542.

Chiovenda, G. (1977). Principios de derecho procesal (Tomo II). Madrid: Reus.

Cifuentes, S. (1991). Negocio jurídico. Buenos Aires: Astrea.

Compagnucci de Caso, R. H. (1980a). Condición tácita impuesta por la ley y cláusula penal. Revista Notarial, Publicación del Colegio de Escribanos de la Provincia de Buenos Aires, (852), 1544-1551.

Compagnucci de Caso, R. H. (1980b). Obligación y responsabilidad. Revista Notarial, Publicación del Colegio de Escribanos de la Provincia de Buenos Aires, (853), 2089-2120.

Compagnucci de Caso, R. H. (1992). El negocio jurídico. Buenos Aires: Astrea.

Compagnucci de Caso, R. H. (1994). El silencio como manifestación omisiva de la voluntad, La Ley, 1994-D, 312-317. 
Compagnucci de Caso, R. H. (2001). La relación jurídica: derechos subjetivos, deberes jurídicos y obligación. J. A., número especial, (25-IV), 1180-1195.

Compagnucci de Caso, R. H. (2009). Prescripción. Estructura y fundamentos. La Ley, 2009-A, $1119-1124$.

Compagnucci de Caso, R. H. (2016). Comentario al artículo 896. En Bueres, A. J. (Dir.), Código Civil y Comercial de la Nación y normas complementarias. Análisis doctrinal y jurisprudencial (Tomo II-B). Buenos Aires: Hammurabi.

Compagnucci de Caso, R. H. y Moreno, V. (2016). Comentario al artículo 257. En Bueres, A. J. (Dir.), Código Civil y Comercial de la Nación y normas complementarias. Análisis doctrinal y jurisprudencial (Tomo I-B). Buenos Aires: Hammurabi.

Couture, (1981). Fundamentos del derecho procesal civil (3 $3^{\text {a }}$ ed.). Buenos Aires: Depalma.

Coviello, N. (1938). Doctrinas generales del derecho. México: Uthea.

De Castro, F. (1984). Derecho civil de España. Madrid: Civitas.

De Castro, F. (1985). El negocio jurídico. Madrid: Civitas.

De Gasperi, L. y Morello, A. M. (1964). Tratado de derecho civil (Tomo I). Buenos Aires: Tea.

De Ruggiero, R. (1931). Instituciones de derecho civil (Tomo I). Madrid: Reus.

Devis Echandía, H. (1974). Teoría general de la prueba judicial (Tomo I). Buenos Aires: Zavalía.

Ennneccerus, L. y Nipperdey, H. (1966). Parte general. En Enneccerus, L., Kipp, T. y Wolff, M. (Eds.), Tratado de derecho civil (3a ed., Tomo I). Barcelona: Bosch.

Espín Cánovas, D. (1977). Manual de derecho civil español. Parte general (6a ed., Tomo I). Madrid: R.D.P.

Falzea, A. (1941). La condizione e gli elementi dell'atto giuridico. Milán: Giuffre Editore.

Flamma, M. (2014). Comentario al artículo 2289. En Rivera, J. C. y Medina G. (Dirs.), Código Civil y Comercial de la Nación comentado (Tomo VI). Buenos Aires: Thomson Reuters/La Ley.

Flume, W. (1998). El negocio jurídico. Parte general del derecho civil. Madrid: Fundación Cultural del Notariado.

Ferrer, F. A. M. (2016). Comentario al artículo 2289. En Alterini, J. H. (Dir. gral.), Código civil y comercial comentado. Tratado exegético (2a ed., Tomo XI). Buenos Aires: Thomson Reuters/ La Ley.

Galgano, F. (1988). Il negozio giuridico. En Cicu, A, y Messineo, F., Trattato de diritto civile e commerciale. Milán: Giuffre Editore.

Galgano, F. (1992). Diritto privato. Pádova: Cedam.

García Amigo, M. (1979). Instituciones. Parte general. Madrid: Editorial Revista de Derecho Privado. Hidaldo García, S. (2015). La adquisición de la herencia. En Hidalgo García, S., Martínez Escribano, C., Crespo Allue, F. y Fernández-Prida Migoya, F., La sucesión hereditaria y el juicio divisorio. Madrid: Thomson Reuters/Aranzadi.

Lacruz Berdejo, J. L. (Dir.). (1984). Elementos de derecho civil. Parte general (Tomo I). Barcelona: Bosch. Larenz, K. (1978). Derecho civil. Parte general. Madrid: Revista de Derecho Privado.

Lehmann, H. (1956). Tratado de derecho civil. Parte general. Madrid: Revista de Derecho Privado. López Herrera, E. (2007). Tratado de la prescripción (Tomo I). Buenos Aires: Lexis Nexis.

Llambías, J. J. (1975). Tratado de derecho civil. Parte general (5 a ed., Tomo II). Buenos Aires: Perrot. Machado, J. O. (1898). Exposición y comentario del Código Civil (Tomo III). Buenos Aires: Lajouanne.

Maiorca, C. (1961). Fatto giuridico. En Novissimo Digesto Italiano (Tomo VII). Turín: UTET. 
Mariani de Vidal, M. (1995). Curso de derechos reales (3a ed., Tomo III). Buenos Aires: Zavalía. Mayo, J. (1988). Comentario al artículo 896. En Bueres, A. J. (Dir.), Código Civil y Comercial de la Nación y normas complementarias. Análisis doctrinal y jurisprudencial (Tomo II-B). Buenos Aires: Hammurabi.

Messineo, F. (1954). Manual de derecho civil y comercial (Tomo II). Buenos Aires: EJEA.

Moisset de Espanés, L. (1998). La prescripción adquisitiva o usucapión. J. A. 1998-A-320.

Moisset de Espanés, L. (2004). Prescripción. Córdoba: Advocatus.

Morello, A. M. (1990). En torno a la prueba. La Ley, 1990-E, 1071-1077.

Natale, R. (2012). Reflexiones sobre la aceptación y renuncia de la herencia en el Anteproyecto de Código civil. J. A., III(V), 1299-1309.

Orgaz, A. (1950). Concepto del hecho jurídico. La Ley, 59(892), 892-898.

Orgaz, A. (1963). Hechos y actos o negocios jurídicos. Buenos Aires: Zavalía.

Ossola, F. A. (2018). Obligaciones. En Rivera, J. C. y Medina, G. (Dirs.), Derecho civil y comercial. Buenos Aires: Thomson Reuters. Abeledo Perrot.

Palacio Lino, E. (2011). Derecho procesal civil (2a ed., Tomo IV). Buenos Aires: Abeledo Perrot.

Perrino, J. (2010). Derecho de las sucesiones (Tomo I). Buenos Aires: Abeledo Perrot.

Pizarro Ramón, D. y Vallespinos, C. G. (1999). Instituciones de derecho privado. Obligaciones (Tomo III). Buenos Aires: Hammurabi.

Prieto Molinero, R. (2014). Comentario al artículo 257. En Rivera, J. C. y Medina, G. (Dirs.), Código Civil y comercial de la Nación comentado (Tomo I). Buenos Aires: Thomson Reuters/ La Ley.

Puerta de Chacón, A. (2015). Prescripción adquisitiva. Aspectos innovadores del nuevo régimen legal. Revista de Derecho Privado y Comunitario, (1), 71-118.

Pugliatti, S. (1996). I fatti giuridici. Milán: Giuffre Editore.

Puig Brutau, J. (1978). Fundamentos de derecho civil (2a ed., Tomo I). Barcelona: Bosch.

Rivera, J. C. (1995). Instituciones de derecho civil. Parte general (Tomo II). Buenos Aires: Abeledo Perrot.

Ruiz Serramalera, R. (1979). El negocio jurídico. Madrid: Publicaciones de la Universidad Complutense.

Salas Acdeel, E. (1944). Prescripción, caducidad y plazo preclusivo. J. A., I(336).

Salvat, R. y López Olaciregui, J. M. (1964). Tratado de derecho civil argentino. Parte general (Tomo II). Buenos Aires: Tea.

Salvat, R. y Romero del Prado, V. N. (1954). Tratado de Derecho Civil argentino. Parte general (10a ed., Tomo II). Buenos Aires: Tipográfica Editora Argentina.

Santoro Passarelli, F. (1964). Doctrinas generales del derecho civil. Madrid: R.D.P.

Santos Briz, J. (1978). Derecho civil, teoría y práctica (Tomo I). Madrid: R.D.P.

Savigni, F. C. (1878/1879). Sistema de derecho romano actual (Tomo II). Madrid: Góngora.

Sconamiglio, R. (1954). Fatto giurico y fattispecie complessa. Rivista Trimestrale di diritto commerciale e civile.

Sconamiglio, R. (1969). Contributo alla teoría del negozio giuridico. Nápoles: Jovene.

Spota, A. G. (1967). Tratado de derecho civil. Parte general (Tomo I). Buenos Aires: Depalma.

Tobías, J. W. (2016). Comentario al artículo 257. En Alterini, J. H. (Dir. gral.), Código civil y comercial comentado. Tratado exegético (2a ed., Tomo II). Buenos Aires: Thomson Reuters/ La Ley. 
Tobías, J. W. (2018). Tratado de derecho civil. Parte general (Tomo III). Buenos Aires: Thomson Reuters/La Ley.

Torrente, A. y Schlesinger, P. (1999). Manuale de diritto privato (16 ${ }^{\mathrm{a}}$ ed.). Milán: Giuffre Editore. Trabucchi, A. (1967). Instituciones de derecho civil (15 a ed., Tomo I). Madrid: R.D.P.

Von Thur, A. (1947). Derecho civil. Teoría general del derecho civil alemán (Tomo II). Buenos Aires: Depalma.

Zannoni, E. (2008). Derecho de las sucesiones (5a ed., Tomo I). Buenos Aires: Astrea.

Zatti, P. y Colussi, V. (2001). Lineamemti di diritto privato (8 ed.). Pádova: Cedam. 